\title{
Shifting Trend of Mithila Painting: Tradition to Contemporary
}

Raj Kishor Singh

Ph.D

Assistant Professor

Central Department of English

T. U.

Kirtipur, Nepal

drrksnp@gmail.com

\begin{abstract}
This article communicates the changing pattern of Mithila folk painting to fine art due to the professionals' intervention in this realm. Besides, technological use has further altered it and the people who were unable to perform their ritual on the works of art are able to do so now. Consequently, the painting has been enhanced from its limited geography to all over the world where even the diaspora Maithils enjoy their culture with full enthusiasm. This phenomenon has led people both connected to their culture as well as uplifted to high spirituality, aware about their identity and commercializing their cultural artifacts. Thus, this fluctuating tendency of this folk art has empowered the community morally, artistically and economically.
\end{abstract}

Keywords: Mithila Painting, Technology, Professionalism, and Empowerment

Introduction

The rapid change in education and technology has brought remarkable modification in the presentation of Mithila art. Before 1960s, it used to be a collective phenomenon where 
illiterate women of rural area used to draw this iconic and abstract painting on the walls and floors of their mud house. After 1960s its transformation on paper brought individual approach in it and gradually educated male and female advanced it professionally. It gained further height when architect, engineer, and other professionals made it their regular part time job at different cities in the world. In this way, Mithila art represented not only the Mithila culture but also the custom of the place where it began to be practiced. But the recent technique is to use local symbols to convey global issues such as feminism, climate change, terrorism, and malevolent effects of natural disaster. This article takes into account only one major forms of Mithila art—painting.

From the confined region of Mithila, it has spread at every prominent place of the world. It has its museum at Japan, Ethnic Art Foundation and institutes in the United States of America, France, Germany, England, Mauritius and many other countries of the world. Locally, Janakpur Women Development Centre is the organization established with the help of some foreign donors with the help of American lady Claire Berket. Although this centre has encouraged some illiterate women of the area, there should be some competitive organizations so that women could compete for higher remuneration. Mostly the rural artists do not get profit according to their hard work day and night but the middle men who do trade on commission basis. Government agencies must be established to cater the need of genuine artists in the field so that they can either go for exhibition of their paintings or can get fixed price of their works.

But the changed scenario and professional development in the field have made the artists expertise in all the techniques, styles, mediums, and forms irrespective of their castes, background knowledge, and gender. Mithila painting has been hatched as a tool to depict varieties of contents that has enriched the scope of this age old art. The incorporation of various modes has only flourished it without damaging its originality. The innovativeness in 
its creation has further maintained the tradition instead of outdating its previous form. Hence, several changes in this genre have strengthened and enhanced Mithila painting at present context.

Problems

Mithila art has continuously been evolving and it has further accelerated after its transformation on paper, canvas and cloth from the mud floors and walls. The commercialization of this art has not damaged its originality but it has enriched with varieties in subject matter, style, and colours use. Although art should be made for art sake, these days, it is made for market. It does not mean that it is losing its aesthetic sense; in addition, it is maintaining tradition with innovation. Mithila painting is no longer the privileged domain of women only; even men have taken to painting in a big way. This statement does not apply now. Similarly there used to be caste wise styles but now the styles are mingled together and any artist can use any medium or technique to create art. Hence, trans-gender, trans-caste, and trans-society are some aspects that have acquired major shift from women centric, caste based, and socially confined traditional painting of Mithila. This work seeks to study Mithila painting in the light of these changes, and tries to explore its socio-semiotic meanings.

It is assumed that Mithila painting has moved away from traditional themes of women's repressed desires and sexuality and fertility to cross-cultural themes in today's globalized contexts. This research will study the evolutionary process of Mithila painting namely its styles, subject matters, forms, and colour combinations. It will further delve into the women's perspective towards society and life through the symbolic use of the art. This research will further comprise the change in livelihood of the artist due to commercialization and the way disruption in art has maintained the tradition of Mithila painting. Although there will be some discussion of the effect of commercialization. 
This research will pave the way for systematic study about Mithila painting and its changing dynamics through the changing age. The fresh look on this age old painting is the motto of this investigation. On Mithila painting, the major focus will be on the socio-semiotic meanings inherent in the paintings by women.

Methodology

This study will use Inductive Analysis Approach using Semiotic Theory, Anthropological sociological theories and Indigenous Arts theory for socio- semiotic Interpretation of the Mithila art. The data for this qualitative research will be collected through interview, textual analysis and observation. It will further incorporate Ontology (multiple Realities) and Epistemology (subjective knowledge ) for Interpretive Paradigm. The following conceptual framework will reveal the methodology clearly.

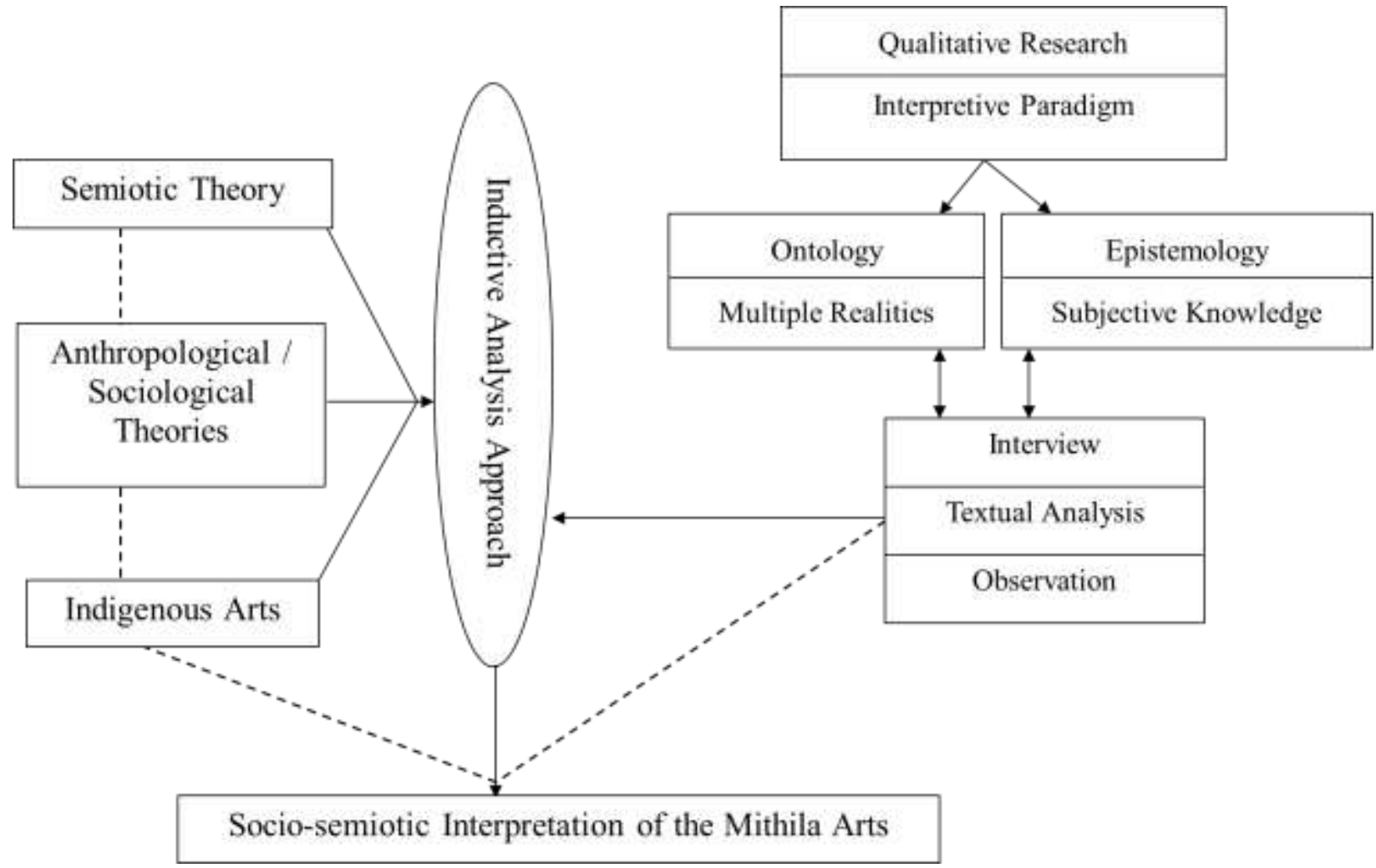

Different aspects of modern society combine to create meaning. These semiotic resources surrounding us include obvious modes of communication such as language, gesture, images 
and music, but also less obvious ones such as food, dress and everyday objects,all of which carry cultural value and significance. And the meaning is created through complex semiotic interactions. Just as in linguistics the focus changed from the 'sentence' to the 'text' and its 'context' and from 'grammar' to 'discourse' so in social semiotics the focus changed from the 'sign' to the way people use semiotic 'resources' both to produce communicative artefacts and events and to interpret them - which is also a form of semiotic production - in the context of specific social situations and practices.

Discussion/Analysis

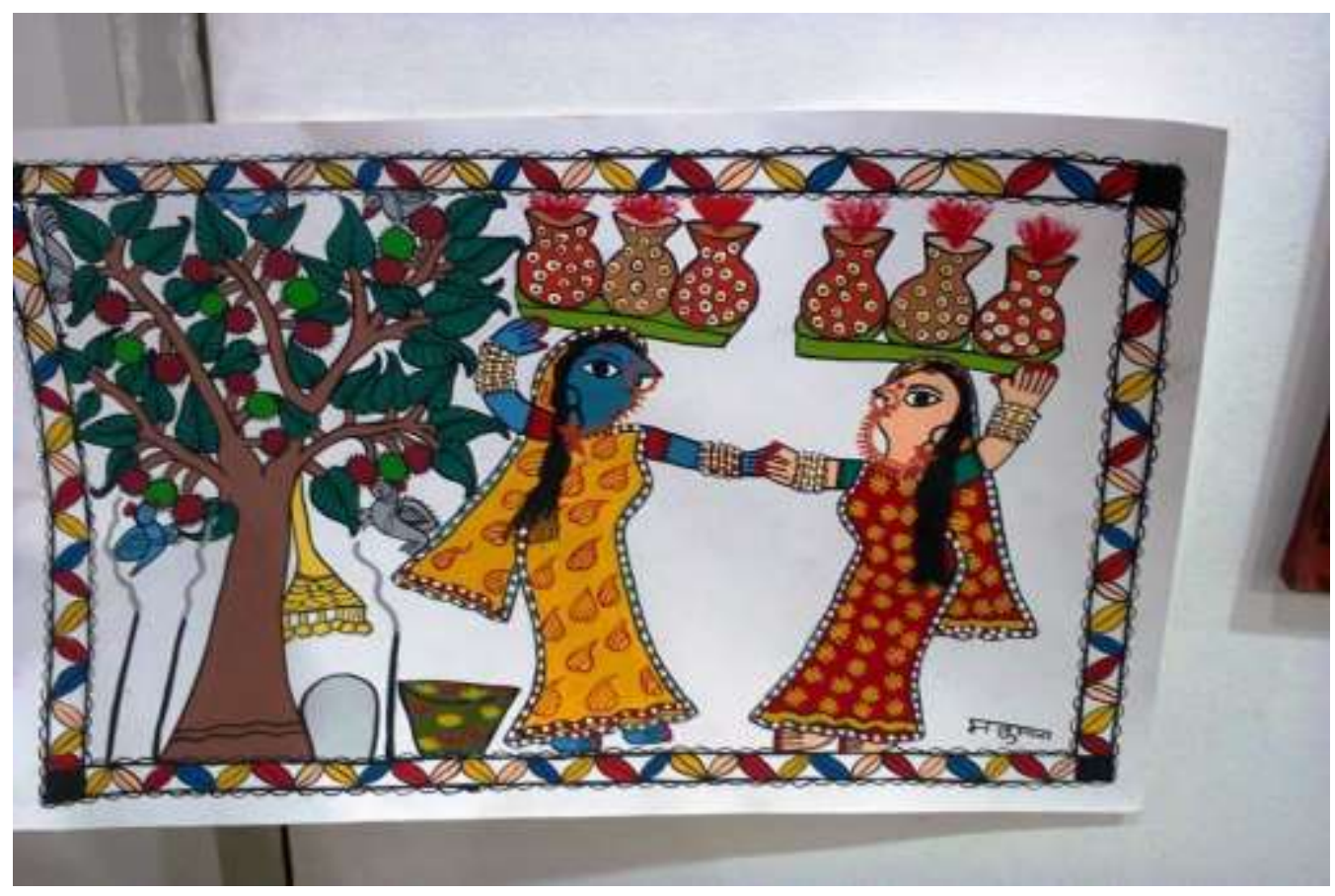

Figure 1 Jhijhiya (Cultural Dance of Mithila)

The above shown Mithila painting is an example of semiotic resource whose meaning becomes clear in a social context. During Dashain (great Hindu festival) Maithil ladies challenge the witch women who seek to accomplish their evil techniques to kill or harm people throughout the year. The ladies shown in the above work of art carries holed pots with lights on their heads and keep on dancing and singing together so that witch women could not count the number of holes in the pot, neither the lady who is carrying the pot will die at that moment. To make evil away these women in Mithila go to the Brahamsthan (village deity) at 
night to urge him to protect them along with their family members from the evil practice of witch women. The artist has depicted the painting very carefully as it happens in villages of Mithila region. Women in the above picture are shown dancing in front of the temple and the Banyan tree. It is customary to have village deity in each Maithili village where villagers pray, offer and appreciate the deity for the protection from the evil force. In this way, Mithila painting expresses both cultural and aesthetic nuance of Mithila region amid surrounding nature.

Currently Mithila painting has surpassed the notion of gender regarding its creation. No doubt, Maithili women have been drawing it from generation to generation for cultural purpose but when the painting has transformed from floor and wall to paper, cloth and canvas it has taken commercial route to flourish where men are equally deft to portray, preserve, and express their feelings, emotions and opinions. They have flourished this art at the level of quenching individual artistic thrust as well as achieving economic need for survival. While doing so, it has not damaged the traditional pattern of painting rather it has added new dimensions that have further pushed it forward to strengthen the existing mode of painting. But Kailash Kumar Mishra writes, "The possibility of any radical assertion of individuality in the modern sense is extremely limited" (95).Instead individuality has catered its global demand and has forbidden exhausting from its zenith which was maintained in 1970s and 1980s. Mithila art used to be a communal activity before fifty years but now the scenario has changed, artists have begun to play with innovative styles, forms, colours and issues so that they can maintain both the tradition and glory of the land.

The commercialization of painting has given the feeling of rootedness to Diasporas wherever they live at any corner of the world. Since they buy the works of art and hang them on their walls so that they can associate themselves with the distant land and culture of their origin. In this regard, CK Lal mentions, "The diaspora wants to carry a piece of Mithila to 
wherever they live, and paintings are the most convenient way of living with the illusion of rootedness" (10). They also feel pride and create identity out of the exuberant paintings of their land. He further notes about Maithili women and their paintings, "Aesthetics was an integral part, but the point was to express suppressed emotions rather than impress viewers with artistic prowess of the painter" (10). His points can be partially agreed because the sense of beauty is prevalent in the arts of women but there is no vehement way of expression of their emotions through the paintings rather the deities are portrayed to protect them from malicious nature. They do draw celebratory paintings but the art of personal emotion is hardly seen in the cultural paintings of village women.

In contemporary usage, Mithila painting is practiced to aware people from social problem, health hazard, gender issue, economic class, and educational obstacle. It is not confined within the cultural phenomena rather it has advanced its scope at global level to alert people from possible danger and also to adopt safety for living. Mithila painting is not only rooted in its traditional representation as Lal mentions, "In contemporary usage, the term Mithila painting stands for a curious amalgam of frescoes, line drawings, floor decorations and ceremonial art made for rites of passage" (10). But it is evolving as a creative expression of the artists with inventive styles, forms, and themes for aesthetic and commercial purpose. Gradually, it is exceeding the traditional boundary, not to be away from it rather to make it rich in practice and scope for coming generation so that they can shine even away from their limited land and culture to the entire world. However, his major statement, "Mithila painting has evolved over the millennia from mono-color beginning of random lines that were once drawn on freshly washed brown earth with finely ground rice paste" seems convincing as it is still practiced in the Maithili villages (10). Hence, the thought of Maithili artists and people are gradually humanizing after the use of paper and ink for the painting. 
Although the Middle age Maithili literature in general has adopted humanistic approach, Vidyapati played a special role to inculcate it among Maithil folks. Then it also appeared in Maithili art and culture but the modern age has provided it a new look so that people can have myriad forms of benefit from it like visual, cultural, fashion, and educational. For example,

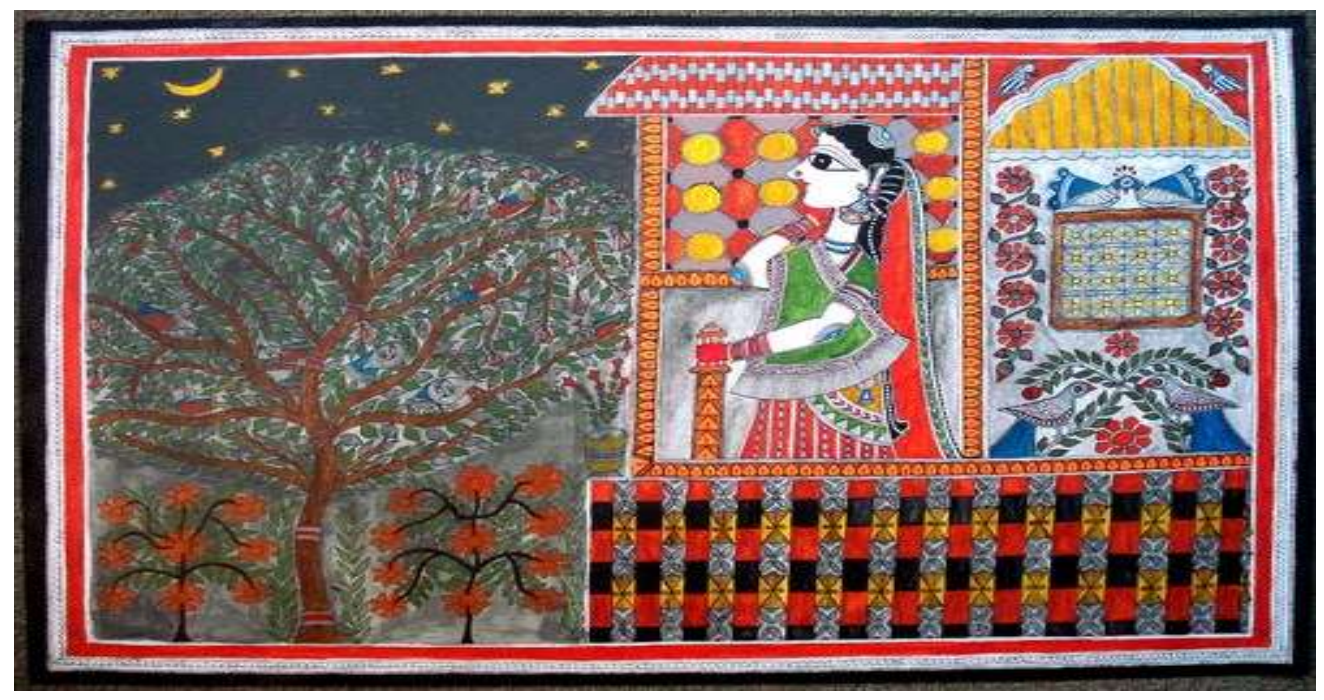

Figure 2 Gazing at the Moon

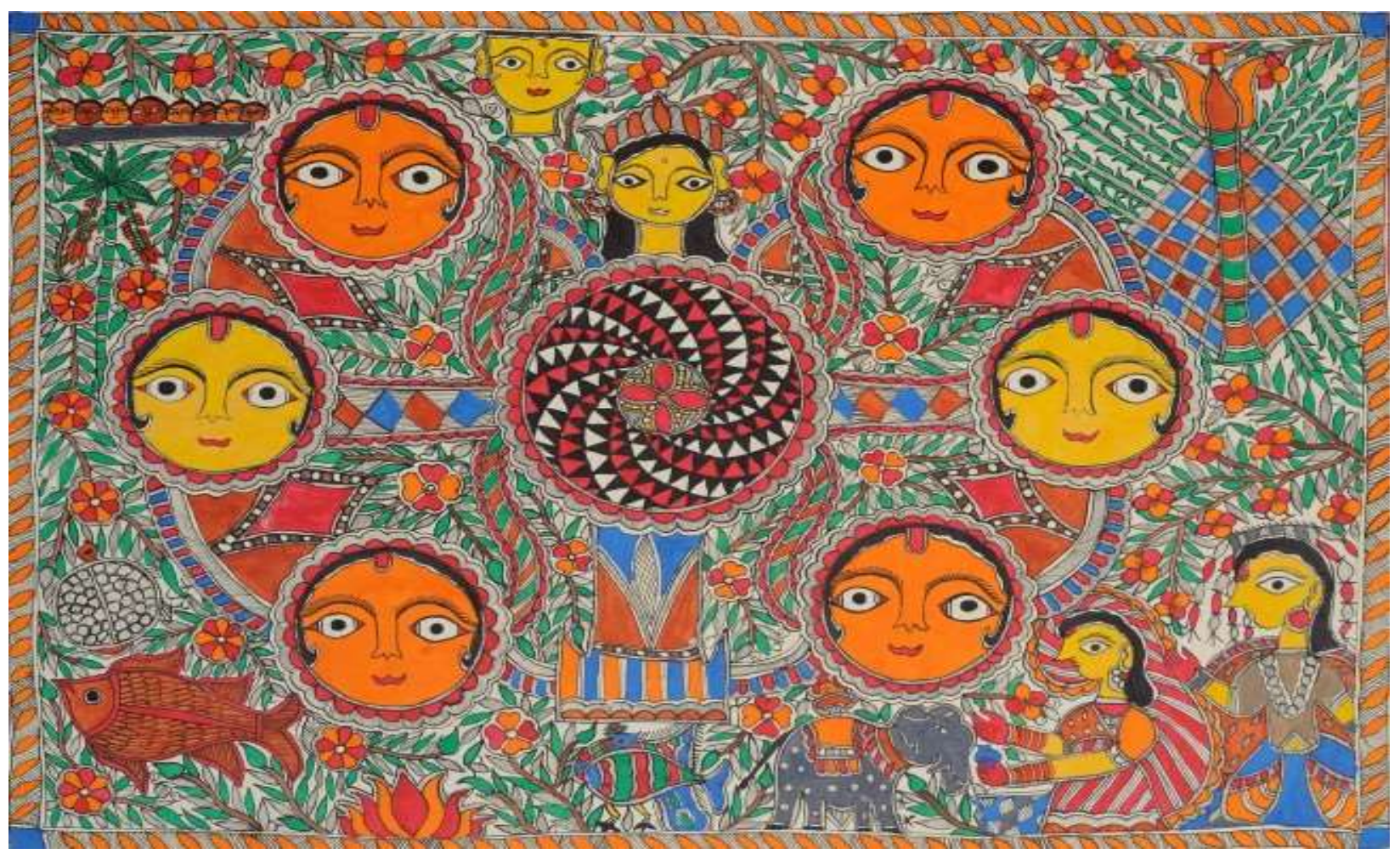

Figure 3 Kohbar - Auspicious Marriage Diagram 
Mithila art is evolving so rapidly that one of its forms developed into Madhubani painting and now it is a kind of tool that can depict any culture modifying in its style quite original to the land. In this context, Nibedita Das writes, "What is however distinct is the innovations in the Madhubani painting to depict Mauritius culture and history" (3). Likewise, we can portray any culture of the world using Mithila painting. This will lead thematic advancement in the Maithili works of art.

Various changes in the region due to educational advancement are jolting Mithila art towards the paradigm shift from folk art to fine art. Even the lower castes have begun to paint and invent a new tradition of their own despite the lack of education but the political changes around them have influenced so much that their legacy is being established through image formation. Whereas upper caste painters are emerging as individual artist gradually modifying the age old art into fine art. In this context, Neel Rekha quotes Mathur, "The kulina art of Mithila has refinement, continuity and a literary base which one cannot expect in the tribal art or in the folk- art of village people"(9). Not only the upper castes but the educated artists irrespective of their castes have developed deftness to transform this art into a fine art. In addition, the interaction of upper and lower castes artists have secularized Mithila painting and has enriched it with variety of all sorts. Rekha mentions, "The entry of Jogin culture in upper caste households was an important evidence of the interaction of upper castes with subaltern beliefs and practices" (8). However, this type of phenomena is traditional in origin the modern trend has accelerated the exchange of styles between high tradition and little tradition.

The followers of little tradition portray folk painting but the upper castes artists who are educated and utilize modern ideology while depicting the painting can be said inclined towards fine art. Although the artists have migrated to towns and cities as well as to different foreign countries, they still practice the local symbols to articulate their opinions about 
different contemporary issues. But Archana Verma writes, "Today, the studies on folklore take the view that the 'folk' comprises the marginalized sections of the society who have not been able to benefit from the modern technological knowledge system" (33). The argument about upper castes Maithili women artists are that they have social status then also their art is called folk because of their marginalized situation in Maithili patriarchal society despite their higher status. Rekha further states, "It is being argued that Maithil painting is no longer a folk art but has transformed into a fine art. While these changes have created fresh interest in this art, certain questions are being raised by Maithil traditionalists regarding the true nature of Maithil art" (6). The complete transformation of Maithili folk to fine art will take time because of the other factors that define 'folk' in particular. In this regard, Verma further mentions, "the definition of 'folk' for these paintings does not only deal with their style of depiction but also with their position in the dynamics of power relation within the community" (39). Hence, the mind of the artists should not be reserved due to cultural matters if it is so, they cannot transform the art into fine one.

The contemporary Mithila painting depends on individual consciousness towards his surroundings. In this context, Sunish et al. write, "The last forty years have shifted Madhubani art from a community religious visual practice to a form of individual creative expression" (4). Manisha Jha, an architect cum artist, introduces techniques from architecture and symbols from traditional Mithila painting to express her feminine issue. Similarly, Urmila Devi Paswan practices her own caste 'Dushadh' tradition of Goidana body art style on Madhubani painting. Likewise, Sunish et al. further describe, "Chandra Kala Devi's work presents close observation of human and animal behavior; her images border on realism and she uses minimal colours even as she retains typical Madhubani space and scale" (4). In the same way, Gopal Saha prefers to draw painting with male pursuits and situations, and performs the drawing with mature skill and vision. For example, 


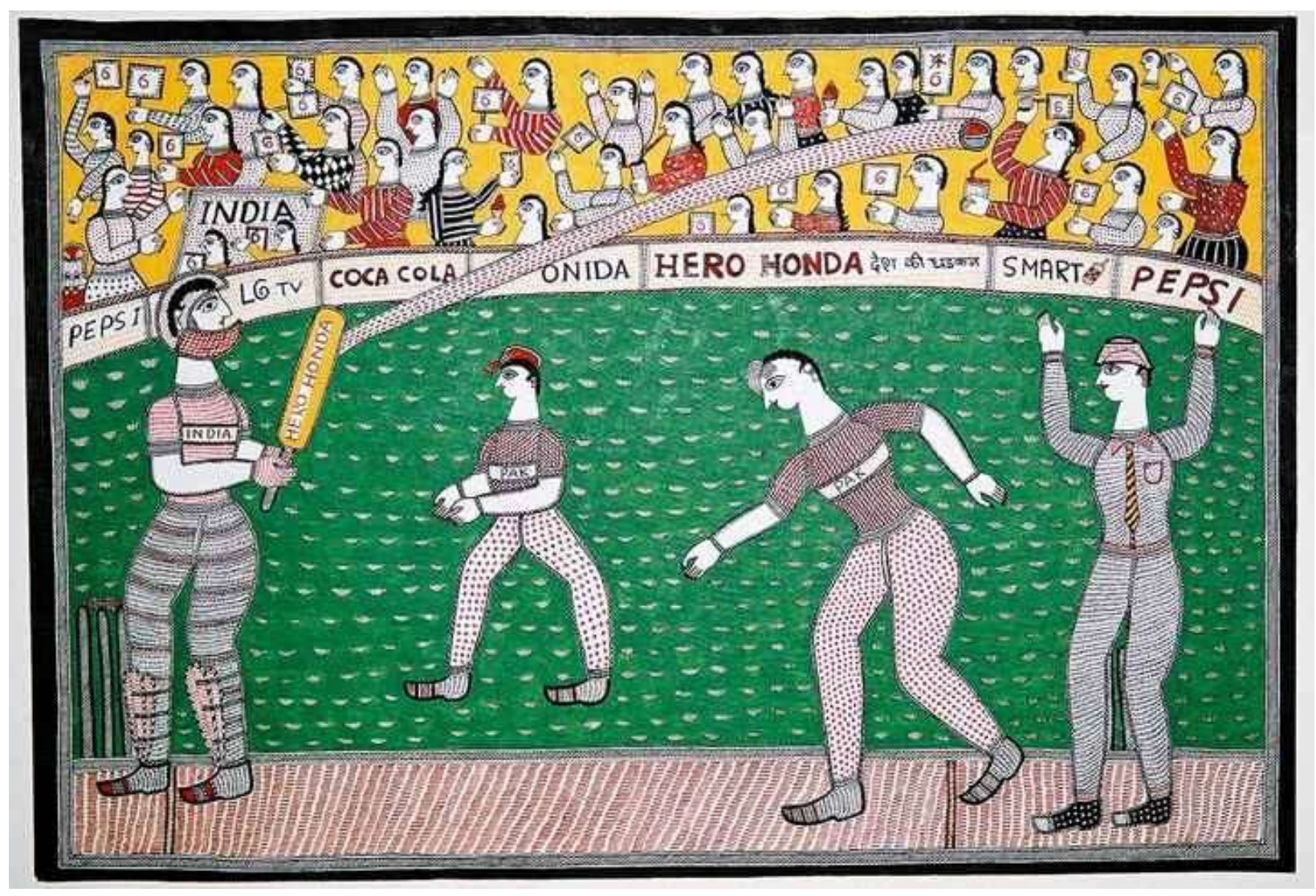

Figure 4 The Cricket Match

The Cricket Match is a public event these days. So, the above painting is made using a style based on Mithila painting.

Furthermore, the interpretation of Kohbar painting from the western interpreters as well as their male informants from Mithila seems away from the female perspective on it. Kohbar painting appears to be full of sexual symbols from male perspective whereas female interpreters find it as the representation of fertility and Goddess Laxmi who fertilizes the soil for agriculture. She is believed to promote health, fertility, long life, and prosperity. Sunish et al. cites Carolyn Hennings Brown:

The whole drawing of purain, then, is a metaphor of the women's own fertility; the fertile, hidden depth of the pond, so productive of life forms, is like the woman's mysterious fertility that produces new life for the husband's lineage. This is a metaphor the men seem never to have understood. 
This may be true from female perspective but it seems hard to digest from male perspective. It does not mean that men have not understood the contribution of female for the family rather it is the cultural practice which is in existence traditionally.

Mithila paintings have survived the test of time. Hindu rulers ruled over the region for a long time (1097 onwards) and follow the vedic rituals strictly. Therefore, despite the political and geographical isolation, Mithila art remained living among common folks. It was further strengthened by literature of the area especially of Vidyapati' spaadavali (songs) from female's (Radha) perspective where Maithili female folk got inspired for their cultural drawings. In this context, Punam Madhok mentions, "Vidyapati made Radha with her changing moods and subtle emotions Krishna's true heroine. The feminine point of view of these love songs make them especially dear to Maithil brides who learn by heart their favourite songs by Vidyapati” (7). Medieval Mithila was popular for conjugal happiness and getting desired number of offspring. And the cultural practice was paramount, hence, the artistic creation.

Each object used in the painting like colours, ornaments, appearance carry special meaning original to the land. The characteristics of Mithila painting is that the artists should be well informed about the traditional ritual observances. So, Madhok again writes:

Red tends to dominate the colour scheme since it is regarded as auspicious for marriage. The bride, in her traditional red wedding sari, is represented in the lower hand side of these paintings. The bridegroom is painted beside her, often with a blue complexion. This relates him to the Hindu gods, Shiva and Vishnu, who are generally portrayed with a blue skin colour to elevate them from the mundane realm. (1)

It shows that Mithila painting is not like a fine art to use any material artists like, instead, one has to have deep cultural knowledge for its creation. Knowledge of the cultural context is 
quite essential for its formulation therefore if the painting is taught out of local location then the learner should also be made aware about the local practice of the land.

Not only the colours or ornaments but also the flora and fauna used in the paintings have religious connotation. Madhok further writes:

A row of parrots is often painted around the rim of the elaborate mandala or lotus pond. In addition, a pair of male and female birds, usually parrots, who are regarded as the vahanas or mounts of Kama, the Hindu god of love and desire, is placed atop the central lotus stem in a beak to beak union. (3)

It means all the creatures who take part in the commemoration of the Maithili cultural show perform its cultural role in a particular context of the occasion. The above mentioned a pair of parrots symbolize healthy union between the couple.

Mithila painting has been communicative since its origin but recently artists have been using it as a tool to express their motives oriented towards consumer society and the global phenomena. Culturally it was used for the blessing purpose to protect them from the malevolent nature. These days, its various usages like aesthetic, commercial, and cultural to the global audience have added mixed response on the part of artists. Some artists are making the same product for commodity purpose neglecting its aesthetic significance. Hence, its innovation seems stagnant; yet, the artists who work for commissioned works are somehow free to use individual talent while making their art. Therefore, despite the consumer based production the art is continuously evolving since 1970s. Even the cultural art made on paper like kohbar has been used in the form of paper among migrant Maithils at distant land. David L. Szanton writes:

Today, many families, instead of painting a kohbar on the wall of the marriage chamber in preparation for a wedding, commission a kohbar to be painted on paper by one of the local artists, and then simply attach it to the appropriate 
wall. Both artists and buyers insist that as long as the imagery is complete, the painting on paper has the same protective and auspicious power as the same image painted directly on the wall. (4)

Besides its cultural role, it also helps the Diasporas to be rooted to their culture by hanging Mithila paintings on the walls of their homes. Thus, its multiple purpose like decoration, cultural and feeling for native land as well as identity of people are attached with these paintings for Maithili people around the world.

Mithila painting does not only quench the artistic thrust of people but it also acts as an alternate living language both for audience and the artists. Traditionally it was used to appease deities in front of family members but, these days, works of painting go around the globe sometimes even making people aware about global issues like climate change, industrialization, terrorism, tsunami, riots, and so on. Szanton mentions, “Artists understand painting as a flexible language, a medium of expression that enables them to speak to and of themselves, and to the world" (4). Although we cannot do without verbal language, it too has its limitation because it does not express the feeling of people in totality. Therefore, universal expressions like music, dance, and painting are helpful for the people as an alternate mode of expression.

Despite several foreign rulers, colonial mission of the west, and globalization, Mithila art is true to its land. The rigorous influence of the outside world has changed the painting nominally rather it has evolved on its own since W.G. Archer photographed it. In this regard, Szanton writes:

And rooted in these broad traditions, Mithila painting has been quite independent of the Western painting techniques and imagery introduced during the colonial period. In effect, Mithila painting has a long history as an indigenous language of expression. (3) 
Maithili artists rather use traditional symbols to convey current meaning. Instead of drawing Radha-Krishna, they draw women watering Krishna's kadamba tree, as it is the demand of the time to aware people for plantation. Hence, despite its commercial purpose, the age old art of Mithila conveys multifold meanings culture to decoration, identity to commodity, and spiritual to secular.

The artistically designed painting represents multifold meanings through it. One of the paintings by a renowned Mithila folk artist Ganga Devi conveys similar idea about her journey to a religious place 'Badrinath'. In the painting, the artist draws a map of her journey to the religious spot where people go for receiving blessing, observing Brahmanical rites, and liberation from the cycle of birth and death. Although she says that the painting is not for sale rather it is a gift item to someone who has granted life to her. That specific painting can motivate people spiritually, guide him to Badrinath, and pave the way for young artists for novelty in the tradition. Mani Shekhar Singh writes, "Ganga Devi’s Badrinath painting brings to our notice that tradition is inherited through disruptions rather than unanimity" (13).Although authentic form seems to be emphasized while drawing Mithila painting, its continuity does not appear to be refreshing in the changing scenario. Rather its interruptions like in the painting of canonical artist Ganga Devi has largely shaped the form and content of this age old painting.

Not only the distinct meaning and geographical location but also the date and signature on the painting open a new chapter of individual recognition through art. The folk artists did not use to put signature, nor did they use to maintain dates of their paintings rather they used to produce paintings as a communal product. This change in the folk painting of Mithila has brought historical milestone in the life of the artists as well as the specific paintings that can reveal age of its production. Singh mentions, "The Badrinath painting, as already stated, is tied to the biography of the artist through two other graphemes: date and 
signature" (13). Besides, the painting is a meditation to portray spirituality among the viewers in their home who can take religious benefit without going away from their home.

Other aspect of the painting is narrative which is a continuous process of the traditional works of art because Mithila painting is narrative in character where each point carries meaning in the realm of larger perspective of the culture. Although the painting is an example of line drawing (Kachani) practiced among Kayastha, it surpasses the sequence by geometric pattern. In this context, Singh writes, "The Badrinath painting is a sweeping geographical continuum in which no attempt is made to demarcate rigid boundaries, especially those that seek to delimit moments in time" (12). This is the way one constitutes originality in the legacy of a tradition. Although the painting has its unique frame, it reveals the same old pattern of storytelling. Since it conveys how people worship in the temple, the available things there, and the flora and fauna of Mithila is also depicted in the painting despite their absence in the Himalayas. Thus, the painting is a vivid example of folk art of Mithila despite the different location and distinguished change in form and meaning.

During 1970s and 1980s prominent subject matter for Maithil artists were epic stories and folk tales. They used to draw their favorite Gods and Goddesses as a prayer to gain spiritual strength as well as to quench artistic thrust as an outlet of their emotions. Jagdish J. Chavda writes, "Such a vast and rich history of some 5000 years can never be exhausted in the narrative content these Jitwarpuri women cull for their art" (26). Hence, all the drawings had description, artists brought from the oral tradition practiced in the region. Although the women artists were illiterate, they knew all the content of ancient literature because of their oral culture which one can easily learn simply by being part of the community. But the women were confined within the four walls of their home and could not express themselves about their work to the outside world where the male members of the society interfered on the 
behalf of women which marred the exact interpretation of their paintings. The patriarchy was leading the women even at the place of their dominance.

But these days women are quite vocal for their rights because of external exposure as well as high education the women have received in different fields. Now the content of their painting is not limited to their region only but they get topics from $\mathrm{BBC}$ radio and prove themselves not only as Maithils but also the active member of the global community. Women travel far and wide and they are shaped by the progress in the foreign land that has added extra vigor in their work to bring change in their life and community. But they like viewers to have same sort of feeling by looking at their works of art as they experience during their creation. Chavda further writes:

There are no rules or hierarchies of images, and each woman creates according to her own inspiration. Each work is considered a form of personal prayer, perhaps in the same context as a Japanese raigo or the Hindu-Buddhist mandala. The artists believe that viewers should experience the same prayer that they were engrossed in while executing the art.

Although the content of the art has changed, artists have still the same sort of meditative attitude while drawing the art. It seems that they are absorbed in the work like deep meditation. Hence, concentration in the work is always demanding despite the change in time and the scenario. But the rural women who draw art on the mud walls and floors of their house still decorate their mud huts with cow-dung smears, and it is there that the intricacy and richness of their natural talents are best displayed.

The art of Maithils are not confined within the individual artist but it is also the cultural expression of the community. In spite of the change in subject matter, the form of 
expression can easily detect a piece of painting from Mithila folk art. In this perspective, Chavda points out:

In this narrative rug painting, Jagadamba Devi depicts her as Kali, the four- armed black goddess of generation and destruction. Mouth open, red tongue thrust out, and wearing a garland of heads, she is surrounded by all those she dominates. The image is not just a magical fetish for worship but stands for a manifestation of the Supreme Being.

This sort of painting is not merely a piece of drawing but it captures the conscience of Maithil people in general who consider the painting as a source of spiritual inspiration. The deity appears benevolent even in aggressive mood because of humanistic expression the artists formulate to their works of art. Hence the painting becomes complete consonance to the viewers.

Along with cultural expression, artists are empowered after selling their products and have created pleasant environment in the family. The economical progress of these artists has made them capable to send their children in school and daughters in marriage to rich family and the violence has substantially reduced. In this regard, Vinod Kumar Mishra states:

In the present age of globalization where each and every economy of the world is giving emphasis on women empowerment which is not possible by creating employment opportunities for them but to motivate them to go for creating their own enterprise. Women have undergone a radical transformation from merely a homemaker to a dynamic multifaceted personality contributing to the socio-economic growth worldwide. Therefore, a move from family management to 
enterprise management may be easier than a move from paid employment to self-employment. (48)

Mithila painting has made them self-dependent and has also given freedom to express their desires, dreams, expectations, hopes and aspirations. Artists have been able to generate income within their social construct and have made the folk art as one of the vibrant expressions of human emotions.

Conclusion

Narrative paintings of Mithila are no longer only abstract in nature rather it has extended itself from the spiritual connotation to the public awareness, cultural to commercialization, female to beyond gender and identity formation. The empowerment of the artists has further changed the face of family life and ones' culture has become the bread winning tool especially for the needy ones. Mithila painting is like a language with several dialects, yet all the varieties are pronounced as Mithila art of Mithila region. The point to be highlighted is despite the caste wise styles, symbols, pattern of lines and colours, and themes, artists are using them interchangeably. And the alternation which appears to be fetched is its own growth instead of imitation from any foreign land. Moreover, Diaspora will have dual benefit of being rootedness to their culture as well as in the identity formation. The major focus is women's expression via their age old art and the insertion of their power within the confined area of their freedom. Despite the strong boundary set by patriarchy, Maithili women express their subtle feeling (may be protest) using symbols and that consequently shape their family life. 
SMART MOVES JOURNAL IJELLH e-ISSN: 2582-3574 p-ISSN: 2582-4406 VOL. 8, ISSUE 12, DECEMBER 2020

\section{Works Cited}

Chavda, Jagdish J. "The Narrative Paintings of India's Jitwarpuri Women." Woman's Art Journal (1990): 26-28.

Das, Nibedita. "Madhubani Paintings: Its Existence and Possibility." International Journal of Scientific and Research Publications (2013): 1-7.

LAL, CK. "PAPER, INK, THINK." Republica 1 April 2011: 10.

Madhok, Punam. http://www.virginiareviewofasianstudies.com. 8 June 2012. 